\title{
Introduction to the 2019 special section theme: Team-Based Learning
}

\section{Peter G.M. de Jong ${ }^{1}$}

Published online: 6 December 2019

(C) International Association of Medical Science Educators 2019

In 2015, Medical Science Educator introduced "journal sections" on a specific topic. These thematic sections are the successor of the special issues that were published annually in the years before that. The content for the thematic sections is solicited by a special call for manuscripts. This year we are publishing a special journal section dedicated to the topic of "Team-Based Learning."

In this 2019 section, the journal would like to explore best practices from institutions around the world where TeamBased Learning is implemented in the health sciences curriculum. Team-Based Learning ${ }^{\mathrm{TM}}$ (TBL) as an active learning strategy was developed in the 1970s and is organized as modules, each typically consisting of 3 steps: preparation, testing and application. The method is evidence-based and a substantial body of research on TBL has already been published. TBL originally took off in the USA, but nowadays the method is being used in more and more schools around the globe, including medical schools and other health care related curricula.

The journal received over 40 submissions for this special journal section. In this issue of Medical Science Educator, I present to you the first 12 published manuscripts. The remaining accepted manuscripts are still in production or revision and will be published in one of the upcoming regular journal issues. I hope that the articles in this section are of interest to you and will be an inspiration for medical education leaders using this interesting learning strategy.

Peter GM de Jong, PhD

Editor-in-Chief
Peter G.M. de Jong

P.G.M.de_Jong@lumc.nl

1 Leiden University Medical Center, Leiden, The Netherlands 